\title{
STANDARDIZATION OF MACHINING PROCESS PLANNING IN POWERTRAIN PRODUCTION USING A CAD-BASED IT-TOOL
}

\author{
Michael Weyrich \\ DaimlerChrysler AG, Information Technology Passenger Car \\ e-mail: michael.weyrich@daimlerchrysler.com \\ Jing Cai \\ DaimlerChrysler AG, Information Technology Passenger Car \\ e-mail: jing.cai@daimlerchrysler.com
}

\begin{abstract}
Ulrich Berger
Brandenburg University of Technology Cottbus, Chair of Automation Technology e-mail: ulrich-berger@aut.tu-cottbus.de
\end{abstract}

GERMANY

\begin{abstract}
The collaborative computer-aided machining process planning is an element in the process chain of extended enterprises in Automotive Engineering. Meanwhile in practice it is an approach engaged by both OEMs (Original Equipment Manufacturers) and their long-term machine suppliers. In general the form of collaborative organizations between them is based on the continuous work and data flows in machine building.

This paper highlights the modeling approaches and application possibilities of a new digital planning IT-tool, discusses the aspects of its prospective advantages in machining process planning by OEMs and suppliers. This ITTool for process planning is investigated, regarding collaborative planning of machining process for Powertrain production in Automotive Industry. The production transfer line of connecting rod is the studied scenario that is used as an application reference. Comparing with conventional alphanumeric planning, the efficient CAD-based IT-tool provides the users more flexibility and merits with high qualities, such as process structure, 3D-visualization, timing analyze, and machining tool descriptions. Digitalization of machining process planning makes it possible and profitable to standardize the planning process in OEMs internally, and with their machine tool builders, finally enables the reorganized distributed activities of machining process planning.
\end{abstract}

\section{INTRODUCTION}

In the last few years, the competitive capabilities of a company has been shifted from its individual improvements to enhancements of its relevant supply chain. Innovative IT-tools open up new perspectives of collaboration with suppliers in the area of machine tool building. 
The new information technology, especially manufacturing simulation and visualization tools enable OEM (Original Equipment Manufacturer) to push IT beyond its traditional roles, such as limited application areas and methods, in the manufacturing process and to use technology to leverage true business value (Unger, 2003). In future production facility of OEM will be planned, built, launched and operated firstly using full simulation (Haller, 2001).

In the shape of extended enterprises for Automotive Engineering, the machining transfer line for Powertrain production is collaboratively planned and elaborated by both automobile OEM and its long-term machine supplier. The relationship between the supplier and OEM in that field is very close as there are only a small amount of suppliers.

A CAD-based engineering IT-Tool points out the 3D planning of machining process with simple planning functions. Meanwhile an internet-based new cooperation model, using this tool, brings on higher planning efficiency and quality.

\section{PROCESS STANDARDIZATION}

Automotive companies are nowadays under intense global competitive pressure and harsh economic conditions. In automotive industries, the challenge is to develop more new car models in a shorter time (Haller, 2001). Thus, the improvement of business performance is necessitated to evade or minimize the inefficiency and redundancy in the work, with supplier as well, which can be procured through standardization approaches.

The standardization contains technology and process, which is conducted not only in the reorganization of work around processes inside a company, but also in the extension of external processes in the distributed collaborations.

Before application of new information technology, OEM should standardize internal application processes and situate the relevant new IT-tools in work harmoniously. And meanwhile, this kind of new IT application with corresponding processes, triggers the supplier to provide the digitalized product and adjust its intern processes. However, due to the different systems, different priorities and different business culture of all participants in cooperation, the imbalance of IT application levels and the corresponding disconnection of process between them are becoming more evident.

A certain level of standardization from supplier to manufacturer is required to achieve the level of connectivity necessary for a smooth flow of full information, product, and process to obtain tremendous improvements in efficiency and value creation. One of the acceptable solutions is enabled by all-purpose centralized information medium: the technology adapter for continuous data flow and the ubiquitous internet for workflow. Finally, this fulfillment provides all participants with a redesigned connective transparent process with responsibility assignments. Internal or external standardization refers to a certain level of harmonization. In the event of any renewal or amendment in cooperation, standardization should be taken into consideration (Champy, 2001) 


\section{MACHINING PROCESS PLANNING IN POWERTRAIN PRODUCTION}

\subsection{Powertrain Production}

The Powertrain system is a propulsion mechanism in the vehicle which consists of the engines, front axis, rear axis, transmission to drive aggregates. The engine consists of the crankcase, cylinder head, camshaft and connecting rod, etc.

The Powertrain production is conducted by the automobile OEMs in large quantities. More than one thousand units of a special type is typically produced. In general, the production of Powertrain is separated into several courses: rough part casting or foundry; rough part machining; in-process quality control and finish part assembly, etc. The production systems are provided from the machine suppliers (Berger, 2001).

\subsection{Transfer Line for Machining Operations}

The Powertrain components are so geometrically and mechanically complex that the number of machining operations can be very high. For an instance, more than 180 different holes are applied in a design of crankcase, which adds up to about 400 machining operations for drilling. In mass production, the machining operations are usually performed in a sophisticated production transfer line including assorted and capable simple machines.

Transfer line is a technical nomenclature, meaning a production line, in which work pieces are transferred and finished by different machines. The machines are located along the line, according to the organized entire machining step. Each machine executes the commensurate machining operations, i.e. milling, drilling, sinking, tapping, chamfering, honing, grinding, etc. If the machining operations on one machine are finished, the work piece is to be transferred to downstream machine or machines for further machining operations.

A transfer line has a structure with several administrative and organizational levels, which stand for, in a descending order, transfer line, sub transfer line, station, sub-station, machine and so on. The whole machining operations are determined and arranged into the structure of transfer line.

\subsection{Transfer Line Creation in Close Cooperation with Supplier}

Ordinarily the automobile OEM has all kinds of suppliers as long-term business partners, such as machine suppliers, software suppliers, product suppliers, logistic suppliers, equipment suppliers, etc. An "extended enterprise" is shaped in close cooperation with supplier (see Figure 1). The difference between Supply Chain 1 and Supply Chain 2 is the closeness to OEM. In some case the supplier in chain 1 can be the customer for those in Chain 2 .

Transfer line creation of Powertrain production is a work package which is engaged by both Automobile OEM and their machine supplier. The new Powertrain product design of CAD-based construction is accomplished in the product development department of OEM. Simultaneously with regard to the criteria of the product volumes, production cost and timing, the production planner starts 
machining building project. The production planner usually refers to the previous product criteria, and defines production quality, for instance, finish part tolerances. Meanwhile the machine supplier is ordered and responsible for machine building, transfer line delivery and installation. The production planner discusses with supplier about the manufacturing philosophy, checks the plan and feeds back to supplier and vice versa. After final generation of plan from supplier, the production systems are then installed by supplier. The production real-time tests and optimizations are performed by production planner. If all the criteria are fulfilled, the production is then started.

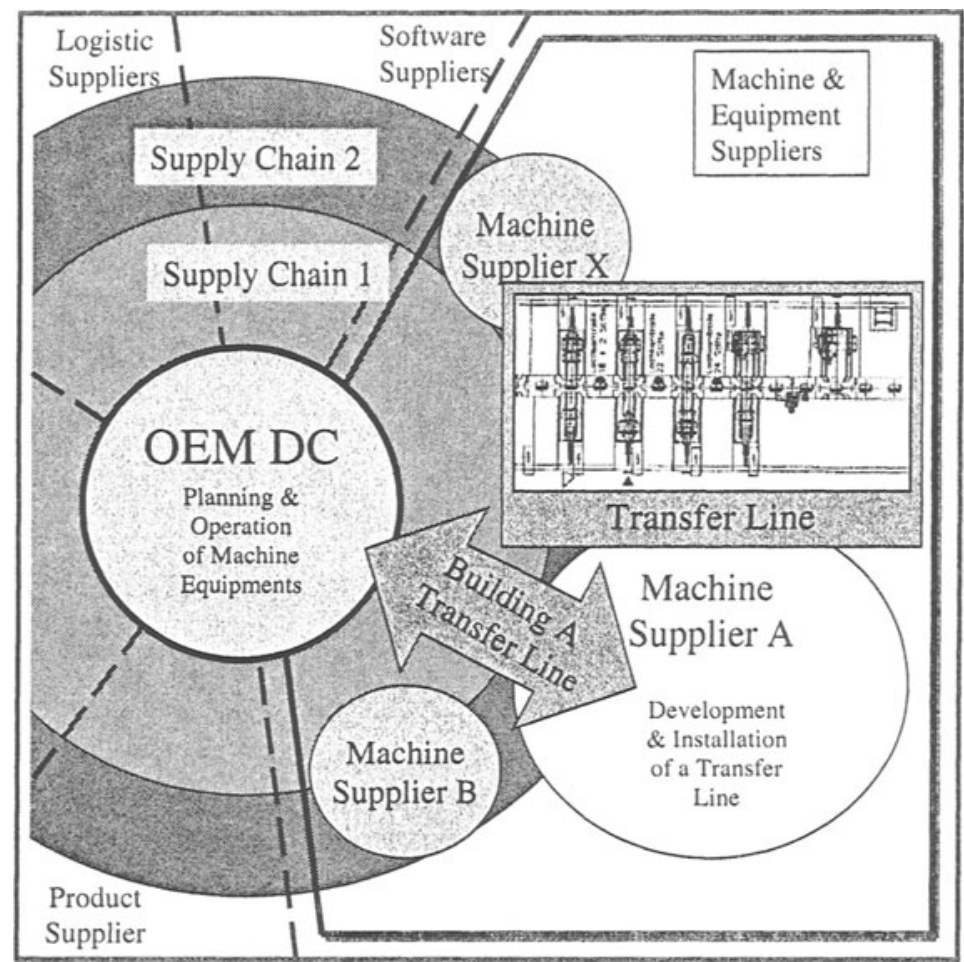

Figure 1 Extended Enterprise in Machining Process Planning

\section{REENGINEERING THE COLLABORATION PROCESS}

\subsection{Process}

The process is one of central elements of a company, along with people, structure, and strategy. It concludes not only the individual business activities, but the interaction with other organizations as well (Champy, 2001). The process of machining process planning for building a transfer line is very complicated. The information exchange process can be concluded as follows. 
During process planning, the machine supplier provides the estimates of machining process in some kind of data tablets and 2D-drawings, which are generated from their own planning IT-Systems. The production planner checks them using his own paper-formed IT-systems, which are different form the supplier's ones and gives the supplier feedback. Holding friendly discussions and frequent meetings, communicating through phone and email are supporting this cooperative transfer line building. With the growing maturity, the final process plan will be decided.

Actually, the information exchange from IT-system to IT-system is a redundant work and lacks information exchange connectivity, which greatly baffles the data and information directly exchanged between them. There is a great challenge of integrating the supplier into a smooth standardized digital data and process flow in the supplier chain with different IT-systems and work philosophies.

Recently, a new information technology for machining process planning, especially for transfer line, is available. This IT-tool is based directly on the CAD construction methodology. The machining process planning of a transfer line can be easily illustrated in three-dimensions, conducted and optimized. It provides users the possibilities to building digital CAD-based machining process plan and even standardize the machining process planning in supply chain.

\subsection{Proposition}

The expected cooperation between the production planner and their machine supplier is based on the continuous work and data flow of machine building. In future, any production equipment shall be installed only after the full simulation and verification by OEM (Haller, 2001). In the machining process planning, a new CAD based computer-aided tool is available. OEM production planner has much interest:

- Because designer develops the product using CAD-based computer-aided tool, which is in the same IT-platform as CAPP-tool.

- The integrated end-to-end computer-aided process chain including design, process planning and manufacturing can be composed.

- Advantages in progress of the actual internal work performances can be foreseen.

If this tool provides more flexibility and merits with high quality, in comparison to conventional planning, the standardization of internal process planning is generally done to situate the new information technology in work harmoniously.

On the other hand, an OEM has many machine suppliers, who have different planning philosophy and IT infrastructures. They would like to use the simple IT tool to fulfill all the requirements from OEM. However, different OEMs may force suppliers to use different IT-tools which adds costs to them. This determines the CAD-based new IT-tool's incompatibility by supplier. With customer and supplier alike, the proposition needs to be flexible and reactive, willing to go the extra mile to find a mutually interoperable solution.

\subsection{Participation}

The basis for participation in supply chain is Standardization of:

Technology: the technical requirements of collaborative engineering are a common shared data format of machining process plan and the technology adapters 
for different IT systems using a standard format. In the transfer line building with supplier, the individual planning IT-system should generate the planning information into a standard format file, which can be read and written by other planning systems.

Process: a way to synchronize the exchange of process planning data and information for a transfer line in the supplier chain is to be constructed. The internet supporting planning process is to be applied. The internet portal should be designed to gain and store the extensive and precise information on the machining building, project status, material needs, learning to interface with their diverse planning systems to keep the chain working smoothly. The participation in this new cooperation model is dependent on open communication, overall capabilities, etc.

The production planner stores and signs the production requirements and standardized information in the common database through a specific portal. The machine supplier can access the internet to obtain for process elaboration. The inprocess results can be stored back and documented with the renewal in the portal. Then production planner fetches the data, verifies the results using own system, makes comments in the portal. The machine supplier gets informed, next work cycle starts continuously. All the information about the cooperation cycles is recorded.

This internet supporting collaboration standardizes the work process and makes it transparent. Redundant work can then be avoided, and responsibility is also assigned clearly. The cooperation in the form of extended enterprise can be highly enhanced.

\section{REALIZATION}

\subsection{Transfer Line Modeling using a CAD-Based Planning Tool}

The machining process planning IT-Tool (CAPP) as an element in the CAx-process chain, connects the end-to-end process between the CAD/CAM/CAQ worlds (Gerken, 2001). Instead of alphanumeric process planning, the descriptions of a machining process in a transfer line using three-dimensional CAD-based process planning tool is available. It is verified in Powertrain production and manufacturing process of connecting rod production is chosen to be modeled (see Figure 2).

This specific tool works on the basis of construction methodology. The design data from CAD systems can be automatically imported into the one-platform process planning module. The machining operation is defined by mapping the design characteristics (Weyrich, 2001), i.e. design holes and blocks with corresponding machining steps, for example, drilling, countersinking and tapping for a hole, rough milling and fine milling for a block. The information of each generated machining step includes the geometrical, technological and functional aspects for the production planer. The machining process modeled in a digital process tree is arranged into a transfer line with the administrative levels. This tool provides the production planner with many new functions: process documentation; generating inprocess models and drawings regarding each process level; timing analysis and optimization using Gantt-chart; process model for further concrete definitions in CAM and CAQ systems. 
In the Powertrain production planning, the quick production maturing with complete and standardized technical and organizational process chain is targeted. This planning tool shows the improved information flow with high planning efficiency.

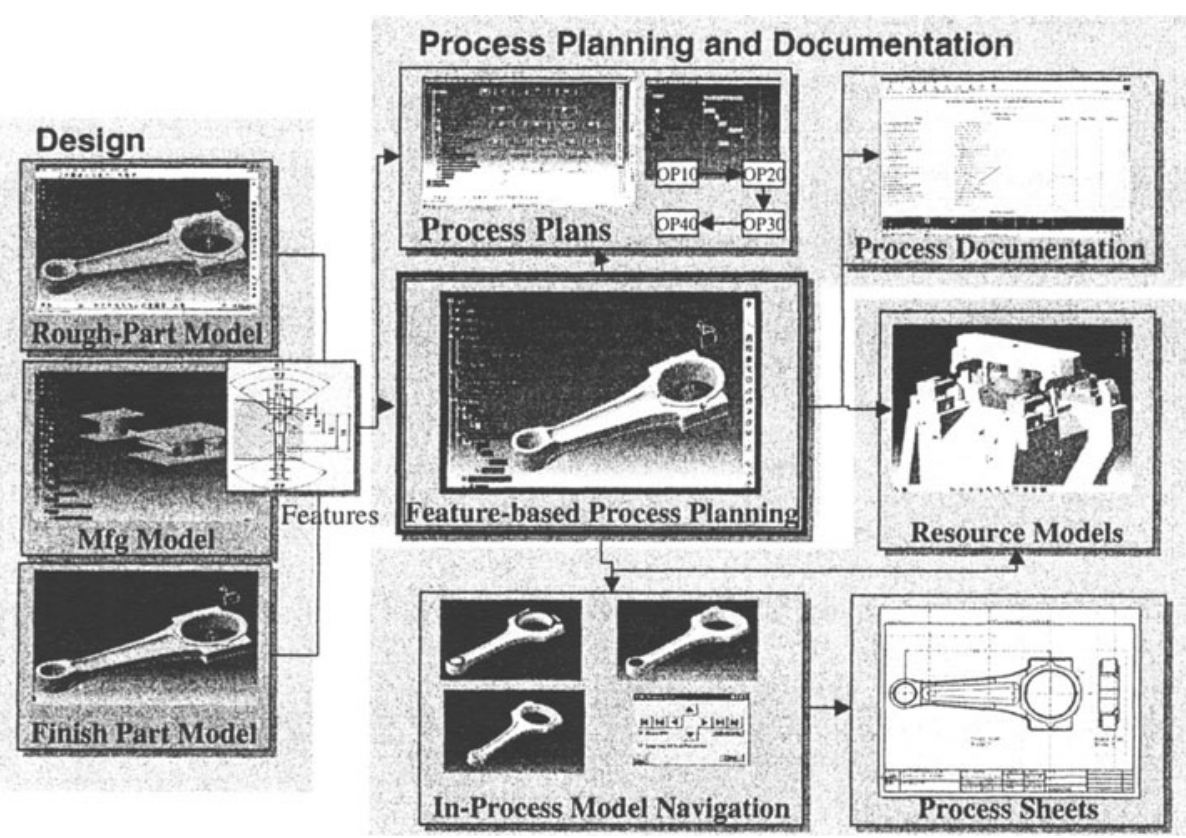

Figure 2 Machining Process Planning - Powertrain Connecting Rod

\subsection{Data Integration for CAD-Based Planning IT-Tools}

Data integration is a fundamental requirement for successful implementation of computer-aided production planning and a decisive factor in the selection of software solutions for the digital plant. Powerful individual solutions can be used to full advantage only when their information is accessible to their applications (Delmia Corp. 2001).

Data base features product, process and resource entities and optional userdefined data views. Information generated by CAD-based machining process planning tool is logically and physically stored in data base once. This data can be made accessible to other manufacturing application or Internet application using an application-oriented database solution. The data that is consistently made available, makes planning process transparent for company-wide use.

The user-defined programmable interface can be used to establish links from the data base to standard software. The data generated from the standard application like MS-office can be easily converted into a data form applied in data base. This programming makes a certain level of data exchange possible. 


\subsection{Machining Process Planning Tool by Supplier}

Naturally, a machine supplier has more than one customer. The cost efficient machining process planning of a transfer line is applied to accommodate different customers with different requirements. In general, the different paper-formed process planning tools such as Excel tablets with some user-defined macros, are frequently used by most machine suppliers.

Excel based IT-package for machining process planning tool without CAD is applied. This includes both serial and special machines. The outcome evaluation is helpful to machine suppliers to plan efficiently (Thomann, 2002) (see Figure 3).

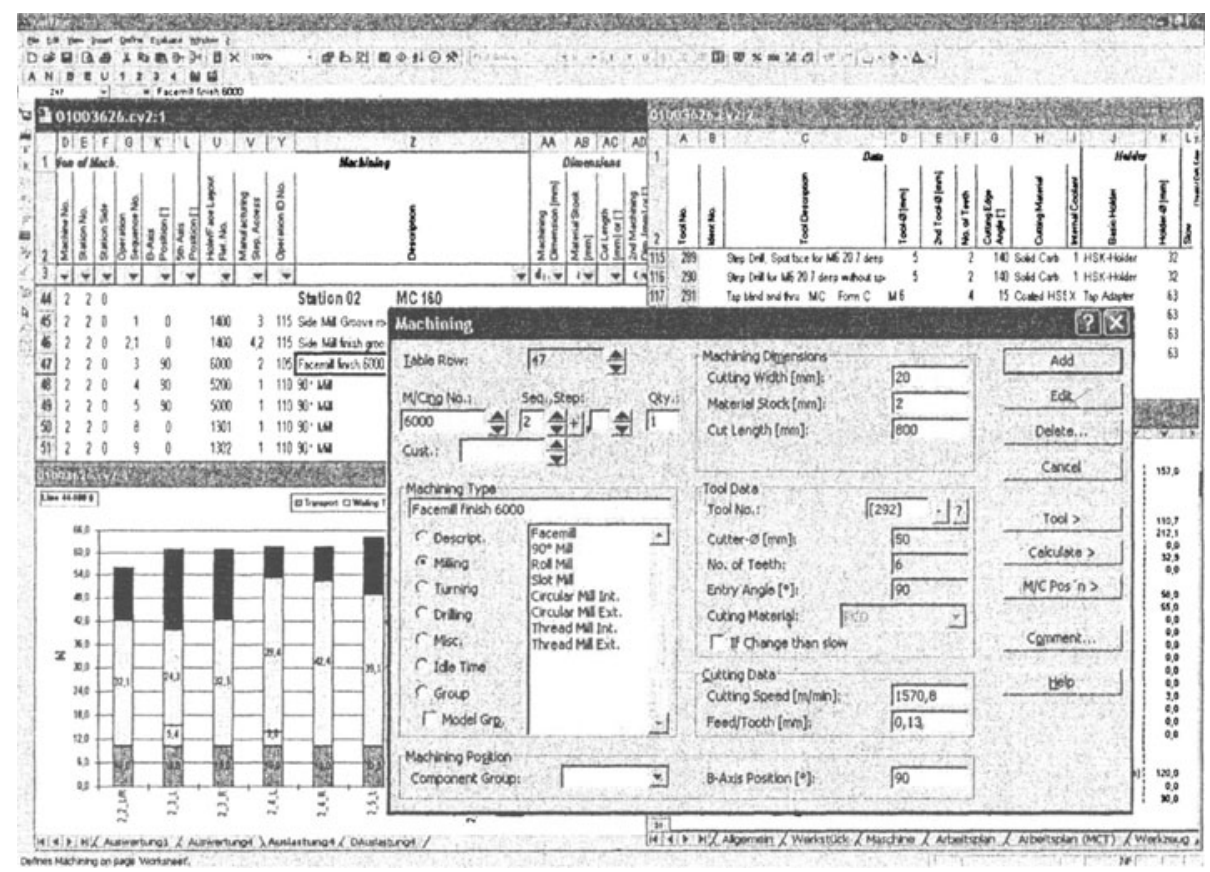

Figure 3 Excel based Machining Process Planning Tool

The individual machining operations are tabulated according to the component drawing dimensions. Parallel to defining the machining, cutting tools may also be defined or selected from an existing tools list. To complete the time study, each machining operation can be arranged in an operation sequence, in a way it will run on the machine. As a result of its open approach, it allows various evaluations to be quickly investigated. Quickly accommodating changes and optimization of a process will be realized easily. with ease. Time studies can be distributed in any data holder that can be exchanged with ease.

\subsection{Internet Supporting Collaborative Data Exchange}

The cooperation model based on internet based IT systems is elaborated to realize the continuous process data exchange for building a transfer line. 
The machine supplier can generate the process plans of a transfer line using own planning IT-systems. The corresponding converters are applied to compile the data formats of process plans into a standard format file. The supplier accesses the a website portal for cooperation of product and production deliveries, and documents the project-relevant information in the portal, saves the standard format process file in the data base with management system. The OEM production planner can check up the renewal, and verify the process plan using own 3D-based planning tool which the data is converted by the specified converter. The new requirements and suggestion can be made and commented in the portal. The whole development procedure and its documents from both sides are clearly presented.

In detail, the standard formatted data is stored in the project-oriented data bank. The upload and download functions fulfill the users to read and save the process planning data. In the portal, the defined blank text boxes or combo boxes ought to be filled out to document who has the actions on process data and when are these actions conducted.

As to the data format converters, a standard Excel tablet is in mind. Almost all of the planning tools by supplier are Excel-based. The only-one-form of process plan is easier to define. From OEM side, the data management with the user defined function supports (reading a file of standard application) is to be implemented. In future, the standardization format, such as STEP standard (Standard for Exchange of Product Model Data) or Step-NC (Standard for Exchange of Product Model Data in Manufacturing), is going to be realized (Weyrich, 2001), due to the application of different 3D-based process planning tool by suppliers (see Figure 4).

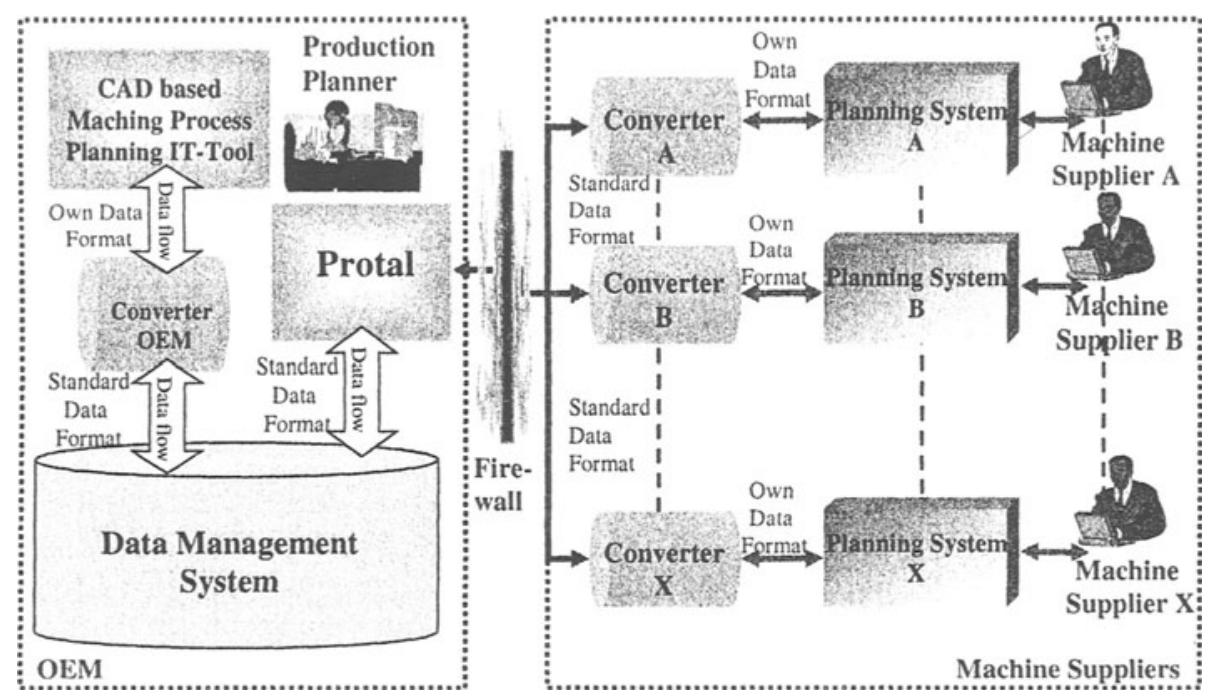

Figure 4 Internet-supporting Supplier Chain Model for Realization of Continuous Process Data Exchange in Building a Transfer Line

\subsection{Using Third-party Products}

The CAD-based machining process planning tool from a software supplier Delmia is applied, which is called DPM-MPP, standing for Digital Production Management- 
Machining Process Planner. Delmia is a strategic software partner of DaimlerChrysler AG. The pilot course to build a transfer line has been done. Delmia's product PPR-Hub is applied as a data base which manages product, process and resource entities and optional user-defined data views. Functionality of PPR-Hub is evaluated for the management of DPM-MPP process data .

CutView is a typical existing solution with Excel format. This tool is built by a machining supplier and industrialized to plan the machining processes in practice. Analysis on the characteristics of this tool have been performed. The connection between CutView and DPM-MPP is composed and in Fig.4 illustrated.

\section{CONCLUSION}

The advantage in this cooperation model provides the OEM and its machine tool builder with continuous data and work flows, improved planning quality and efficiency. The systems' connectivity of collaborative engineering without redundant work integrates the customer and supplier as one.

- The planning process of machining process planning for a transfer line was analyzed, with regard to the cooperation within automobile OEM and its machine supplier.

- The advantage of this new concept is discussed, comparing with today situation.

- The CAD-based machining process planning IT-tool has been tested for standardization of computer-aided process chain. Analysis of a third-party planning tool and its application using the scenario of a connecting rod is done.

- Development of a coupling approach to interconnect the process planning tool with supplier, based on an internet approach is discussed

In the next steps, it is planned to use international standards such as STEP-NC and ISO 10303 to realize the data exchange. The limitation of STEP standards will be further analyzed and corresponding realization using STEP will be in concept.

\section{REFERENCES}

1. Unger S. "Driving the Digital Factory: DaimlerChrysler's Design Automation Push" at the fourth annual Computerworld Premier 100 IT Leaders Conference. Scottsdale, Arizona USA.2003

2. Haller E. "Planning Digitally-Concurrent Engineering at DaimlerChrysler". Fellbach, Germany. 2001

3. Champy J. "X-Engineering the Corporation" Warner Books. New York, USA. 2001

4. Berger U, Lepratti R, "Advanced Factory Automation System for Deburring and Dressing of Automotive Engine Parts". IEEE International Conference on Intelligent Engineering Systems (INES 2002). Opatija, Croatia. 2002

5. Gerken $\mathrm{H}$, Weyrich M. "Management of Experience for CAD / CAM processes using an Assistance System." VDI-Conference "Information Processing in Product Development". Stuttgart, Germany. 2001

6. Delmia Corp. "DS PPR Hub - The Integrated Product, Process and Resource Database". 2001

7. Thomann R. "Infos - CutView2". Lachen, Germany. 2002

8. Weyrich M. "Introduction of the Feature Technology in Powertrain". EDM Forum 2001. eNovative Product Creation, DaimlerChrysler, Fellbach, Germany. 2001

9. Weyrich M, Bates C, Hardwick. "STEP-NC - A new standard for NC programming" American Machinist, The international Magazine of Manufacturing Technology. USA. 2001 